\title{
CONTAR HISTÓRIA(S) E DESPERTAR (IN)VISIBILIDADES: reflexões sobre didática da história, literatura e direitos humanos
}

\author{
Vera Lúcia Silva Vieira* \\ Beatriz Rodrigues **
}

RESUMO: A partir das formulações propostas pela didática da história, este artigo apresenta algumas reflexões sobre a historiografia, o ensino de história e os usos públicos do passado, bem como os desafios que dizem respeito à intensificação dos ataques e das demandas negacionistas na contemporaneidade. Articulando a importância do estudo de temas sensíveis no ensino de história, buscamos o diálogo com as obras K. Relato de uma busca, de Bernardo Kucinski (2011) e A resistência, de Julián Fuks (2015), numa perspectiva que aproxima história, literatura e direitos humanos.

PALAVRAS-CHAVE: Didática da história; Ensino de história; Direitos humanos; Literatura.

\section{Telling story (ies) and awakening (in)visibilities: Reflections about history didactics, literature and human rights}

ABSTRACT: Based on the propositions by the history didactics, this article presents some reflections about the historiography, history teaching, and the public uses of the past, as well as the challenges that concern the intensification of denialist attacks and demands in contemporaneity. Articulating the importance of studying sensitive themes in history teaching, we seek dialogue with the works $K$. Relato de uma busca, by Bernardo Kucinski (2011) and A resistência, by Julián Fuks (2015), in a perspective that brings together history, literature and human rights.

KEYWORDS: History didactics; History teaching; Human rights; Literature.

\section{Contar historia(s) y despertar (in)visibilidades: reflexiones sobre la didáctica de la historia, la literatura y los derechos humanos}

RESUMEN: A partir de las formulaciones propuestas por la didáctica de la historia, este artículo presenta algunas reflexiones sobre historiografía, la enseñanza de la historia y sus usos públicos en el pasado, así como los desafíos sobre la intensificación de los ataques y las demandas negacionistas en la contemporaneidad. Articulando la importancia del estudio de temas sensibles en la enseñanza de la historia, buscamos dialogar con las obras K. Relato de uma busca, de Bernardo Kucinski (2011) e A resistência, de Julián Fuks (2015), en una perspectiva que concilie historia, literatura y derechos humanos.

PALABRAS CLAVE: Didáctica de la historia; Enseñanza de la historia; Derechos humanos; literatura.

\footnotetext{
*Doutora e mestra em História e Cultura Social pela Universidade Estadual Paulista Júlio de Mesquita Filho. Atualmente é professora na Educação Básica e atuou como docente no curso de história da Universidade Federal de Catalão. Contato: Rua Guatemala, 180, Bairro das Américas, Catalão-GO, Brasil. E-mail: veravieira.luci@gmail.com. ORCID: https://orcid.org/0000-0002-1368-7855

**Doutora e mestra em História e Cultura Social pela Universidade Estadual Paulista Júlio de Mesquita Filho. Atualmente é docente do Departamento de História da Universidade Estadual do Centro Oeste. Contato: Rua Padre Salvatore Renna, 875, Santa Cruz, Guarapuava-PR, Brasil. E-mail: bia_sic@hotmail.com. ORCID: https://orcid.org/0000-0002-8784-0330
} 
Não há ignorante que não saiba uma infinidade de coisas, e é sobre este saber, sobre esta capacidade em ato que todo ensino deve se fundar. Instruir pode, portanto, significar duas coisas absolutamente opostas: confirmar uma incapacidade pelo próprio ato que pretende reduzi-la ou, inversamente, forçar uma capacidade que se ignora ou se denega a se reconhecer e a desenvolver todas as consequências desse reconhecimento. $O$ primeiro ato chama-se embrutecimento e o segundo, emancipação.

\section{Jacques Rancière, $\boldsymbol{O}$ mestre ignorante.}

Da epígrafe que introduz o texto chama a atenção a "infinidade" de saberes, seus sentidos e as potencialidades do ato de ensinar que passa pelo reconhecimento da sua complexidade numa perspectiva emancipadora, sem descuidar das dimensões éticas e estéticas envolvidas. Reflexões importantes na medida em que consideramos que a história, como forma específica de conhecimento do mundo, sustentada em rigorosos pressupostos teóricos, metodológicos e científicos, constitui e é constituída também por formas plurais de abordagem da experiência da historicidade humana.

Acompanhando o pensamento de Sonia Wanderley, ${ }^{1}$ concordamos que o conhecimento historiográfico é uma possibilidade científica, mas não a única maneira de "os homens encontrarem sentido para sua existência e construírem representações para o estar no tempo", ou seja, é uma dentre outras maneiras de compartilhar o mundo e construir diálogos possíveis. É sempre bom lembrar que a história é "uma prática social"² antes mesmo de ser atividade intelectual ou disciplina científica. Essa prática é assumida por profissionais que se reconhecem e são reconhecidos como historiadores, além de ser aceita por diferentes públicos.

Ao compreender que historiadores e professores de História são intelectuais públicos, não somente pela operação inerente ao processo de ensino-aprendizagem, mas também por sua atuação na realidade, ${ }^{3}$ descortina-se a necessidade de refletir e problematizar as formas pelas quais o passado encontra eco na atualidade através de violências praticadas, apagamentos e (re)formulações do vivido, além de negacionismos de diversas ordens. Aspectos que sinalizam para desafios éticos, estéticos e políticos que dizem respeito, sobretudo, à elaboração do passado e seus usos públicos e políticos. Dentre os desafios vivenciados na contemporaneidade, como já mencionado, está a crescente produção de 
negacionismos históricos e os ataques aos historiadores e historiadoras, vistos como os inimigos a combater.

Para lidar com a compreensão da pluralidade dos negacionismos em seus âmbitos políticos e sociais, pesquisas amplas, complexas e multifacetadas são necessárias. Embora não seja parte do nosso objetivo aprofundar tais análises, importa considerar e mencionar que as agendas negacionistas têm, cada vez mais, alcançado força em governos de extrema direita e articulam-se, em grande medida, a partir das mídias digitais e mobilizam cada vez mais seguidores. Destaque pode ser atribuído ao papel exercido pelas redes sociais e a velocidade pela qual as ideias são transmitidas e compartilhadas de modo a desqualificar profissionais e saberes largamente construídos no esforço científico. ${ }^{4}$

Essas questões são salutares, em especial, porque tangenciam o ofício da historiografia e do ensino de história, além de provocar diversos questionamentos: como enfrentar a disseminação de negacionismos que, muitas vezes, são amparados por políticas de governo anticientíficas, como lutar contra a instrumentalização política do passado e a reprodução acelerada de canais, sites, perfis e outras mídias que evocam um passado utópico, idealizado, manipulado e politicamente gestado para constranger e deturpar o conhecimento?

O enfrentamento dessas questões exige reflexões de ordem didática, epistemológica, ética e política. A partir das formulações propostas pela didática da história, este artigo apresenta algumas reflexões sobre historiografia, ensino de história e usos públicos do passado. Articulando a importância do estudo de temas sensíveis no ensino de história, buscamos o diálogo com as obras K. Relato de uma busca, de Bernardo Kucinski (2011) e A resistência, de Julián Fuks (2015), numa perspectiva que aproxima história, literatura e direitos humanos.

\section{A didática da história e os usos do passado}

Jörn Rüsen, historiador e filósofo alemão, noz diz que a história está enraizada nas necessidades sociais para orientar a vida prática no tempo e que o entendimento histórico é conduzido pelas demandas do presente. Essas constatações sinalizam para a importância da didática da história, não mais reduzida às questões de ensino e aprendizagem, mas voltada para o conhecimento histórico de forma ampla e em sua relação inseparável com a vida cotidiana e prática, o que também implica pensar acerca dos usos da história e do passado na cena pública. ${ }^{5}$ 
É importante mencionar que não pretendemos, neste artigo, compreender as especificidades e heterogeneidades dos trabalhos produzidos acerca da didática da história, desenvolvidos tanto na Alemanha quanto no Brasil. Adotamos para as reflexões propostas, uma definição mais abrangente, corroborando o pensamento de Rafael Saddi ${ }^{6}$ que interpreta a ciência histórica como objeto constituinte da aprendizagem histórica. Para o historiador, as investigações no campo da didática da história não se restringem ao ensino de história ou às técnicas de ensino, tampouco elas se reduzem ao ensino escolar de história. Além disso, não se trata de uma área externa à ciência histórica que deve buscar em outras áreas (principalmente na Pedagogia) os procedimentos e métodos para definir o ensino de história nas escolas. A didática da história tem se fortalecido mais como um campo de formação prático, que como área cientificamente aprovada.

A didática da história deve pensar e pesquisar os conhecimentos históricos em todo o tecido social, compreendendo as relações que promovem entre si e o conhecimento erudito e/ou escolar. É importante salientar que a didática da história estuda, para além do âmbito escolar, a consciência histórica que é produzida pela sociedade. ${ }^{7}$

Em concordância com Jörn Rüsen, ${ }^{8}$ a consciência histórica pode ser compreendida como "a suma das operações mentais com as quais os homens interpretam a sua experiência de evolução temporal de seu mundo e de si mesmos, de tal forma que possam orientar, intencionalmente, sua vida prática no tempo." Trata-se, portanto, de uma teoria da aprendizagem histórica que almeja refletir sobre os desafios impostos pela contemporaneidade. Afinal, como afirma Luís Fernando Cerri, ${ }^{9}$ "diferentemente do que se imagina no senso comum, influenciado por séculos de uma visão histórica tradicional, limitada e conservadora, a história não é o estudo do passado, nem como ciência nem como ensino. A história é um nexo significativo entre passado, presente e futuro".

Se o ofício da historiografia e o ensino de história estão interligados às ideias, aos questionamentos, às angústias e às produções de consciência histórica do presente, torna-se imprescindível pensar as dimensões éticas e as responsabilidades sociais e coletivas que envolvem as formas pelas quais a nossa sociedade lida com seus próprios passados. Trata-se, por conseguinte, de considerar as múltiplas temporalidades históricas entrelaçadas, uma vez que as diferentes dimensões do tempo (passado, presente e futuro) só podem ser pensadas como indissociáveis. ${ }^{10}$

A preocupação com os caminhos atuais, bem como a urgência da necessidade de reflexões sobre a intolerância e o autoritarismo crescentes no Brasil constituem aspectos 
irrefutáveis para os profissionais da história. Se é recorrente a percepção de que diferentes negacionismos estão em curso na sociedade, no campo da história há a constituição de práticas negacionistas e/ou ideologicamente revisionistas ${ }^{11}$ que colocam em descrédito não somente a prática historiográfica e o ensino de história, como também seus profissionais.

Como nos lembra Walter Benjamin, ${ }^{12}$ articular historicamente o passado não significa reconhecê-lo "tal como ele foi" de maneira exata e exaustiva. Se, em termos epistemológicos, a busca da história não pode ser pelo estabelecimento de uma verdade uníssona e indiscutível e se é da natureza da história a incompletude, a fragmentação e a reescrita, como lidar com negacionismos que colocam em suspenso a nossa prática, o nosso ofício e as evidências da própria história?

Em importante reflexão, Márcio Seligmann-Silva, ${ }^{13}$ aponta que foram muitas as formas e estratégias para se constituir a não inscrição do passado da ditadura civil-militar no Brasil. Além da ausência de uma cultura de memória, Sonia Meneses ${ }^{14}$ afirma que o Brasil está acostumado a esquecer, abrandar e recalcar o passado. Comportamento que é também sustentado "pela falta de cuidado com o patrimônio cultural nacional, museus, centros de memória, arquivos, quase sempre ignorados pelo poder público, mas também pela desconexão de nossa produção historiográfica com setores mais amplos da população".

O Brasil historicamente não tem constituído políticas de memória em relação à ditadura ou tem feito isso de maneira frágil e precária, conforme a perspectiva de SeligmannSilva ${ }^{15}$ e em grande parte da população brasileira ainda prevalece a visão de querer "virar a página" e enterrar a memória do período, impedindo o enfrentamento jurídico e testemunhal. Importante mencionar que durante as atividades da Comissão Nacional da Verdade (20122014) que procurou investigar as violações de direitos humanos no período ditatorial, embora sem poder de punição, o que ocorreu foi uma intensa batalha de memórias em que a negação e o revisionismo ideológico tiveram grande repercussão. ${ }^{16}$

Sobretudo, apesar das limitações da Comissão Nacional da Verdade (CNV), é importante mencionar que ela criou perspectivas para a inscrição, ainda que frágil, de uma memória pública da ditadura civil-militar. De acordo com Caroline Silveira Bauer, ${ }^{17}$ a CNV contribuiu para reforçar a importância das funções sociais do historiador, viabilizou os debates públicos sobre o passado autoritário recente e possibilitou que testemunhos e memórias ganhassem espaço na cena pública. Por outro lado, a partir da comissão houve considerável aumento e disseminação de discursos e representações negacionistas da ditadura civil-militar que se caracterizam, não necessariamente, pela negação da realidade, mas, em 
grande medida, pela busca de justificativas que legitimassem o terrorismo de Estado. Ou seja, a partir da comissão, se intensificam os negacionismos e revisionismos ideológicos que podem ser vistos como reação simbólica para impedir a visibilidade e a fixação dessa memória no espaço público.

As batalhas de memória da ditadura civil-militar de 1964 constituem matéria de constantes embates e inquietações, bem como de múltiplas estratégias que visam à produção do esquecimento. A literatura aparece como espaço possível de interlocução e, neste sentido, buscamos apresentar algumas reflexões a partir de duas obras literárias contemporâneas.

\section{A literatura e as políticas de memória}

O recurso à literatura surge neste artigo "não como fonte histórica no sentido de manancial de informações a serem extraídas pelo pesquisador meticuloso, mas como lugar de boas perguntas acerca de um problema, como lugar de fecundação do pensamento". ${ }^{18}$ A literatura não oferece soluções, não traz respostas prontas e fáceis, mas pode ser lugar de interlocução. Oportuna a perspectiva de Jaime Ginzburg ${ }^{19}$ que reconhece a importância de uma abordagem da literatura que esteja voltada à ética e aos direitos humanos, em especial, num país como o Brasil que "no século XX passou por duas longas ditaduras" e, na atualidade, ainda "sofre com as heranças da tradição patriarcal e dos regimes autoritários". Neste sentido, será que a literatura pode contribuir de alguma forma para o enfrentamento da violência? Ou ainda, a literatura pode contribuir para a constituição e a inscrição de políticas de memória, em especial quando vemos o crescimento de negacionismos históricos?

Temístocles Cezar ${ }^{20}$, ao refletir sobre o tempo presente, os usos do passado e as relações históricas que envolvem eventos-limite, aponta que as técnicas convencionais da história, muitas vezes, não são suficientes para sua compreensão, pois, tais fenômenos constituem experiências temporais tensas, profundas e que provocam fortes deslocamentos e cesuras, os quais, em alguma medida, podem escapar ao escopo da disciplina, levando-a ao diálogo com outras formas de expressão.

Preocupado com o papel da literatura em um país marcado por processos históricos violentos e indiferenças políticas que violam a ética e os direitos humanos, Jaime Ginzburg ${ }^{21}$ questiona as relações da literatura, as experiências traumáticas vividas pela sociedade brasileira do século XX e assinala a urgência do caráter político e ético do ensino de literatura e de história. Para o autor, o que se espera é uma vida literária e histórica - que inclua professores, estudantes, escritores e público leitor - pautada na responsabilidade, na 
necessidade de olhar criticamente para o passado, para os traumas e a violência. Ou seja, elaborar o passado significaria também a construção de uma política de memória literária.

Em um país formado historicamente por traumas, individuais e coletivos, que não puderam ser superados, e que exige uma educação ética, estética e histórica, o teórico indaga:

O que deve ser lembrado, o que deve ser lido? O que tem valor, o que é literariamente importante? [...] Qual voz tem legitimidade para dizer o que deve ser lido, o que deve ser consagrado e lembrado? [...] Que livros devem ser lidos no ensino fundamental e médio, e como devem ser lidos? Que leituras são capazes de respaldar uma formação de cidadania? ${ }^{22}$

Corroborando o pensamento de Ginzburg, dada à constituição social e cultural do Brasil, conformada em práticas autoritárias, hierárquicas e desiguais, é importante estabelecer uma literatura ética e crítica que possa contribuir, juntamente com o ensino de história, na contínua tarefa de elaboração do passado, o que significa não apenas o esforço de compreensão do passado, mas também a ação e a intervenção no presente. ${ }^{23}$

Privilegiando os vínculos éticos e estéticos do ato de ensinar, Fernando Seffner e Nilton Mullet Pereira ${ }^{24}$ destacam o conhecimento histórico, no espaço escolar, como o horizonte da educação em direitos humanos e reconhecem que a escrita da história e seu ensino "não são atitudes desinteressadas, mas voltadas ao futuro - um futuro de tolerância, de reconciliação com a justiça e com os direitos". O estudo de temas sensíveis traz reflexões complexas porque se relacionam com memórias em disputas, injustiças, processos históricos inacabados e que, muitas vezes, envolvem a violação dos direitos humanos. Reverbera a insistência de um passado que não passa e que é sentido cotidianamente na medida em que circunscreve uma espécie de latência e um paradoxo temporal: os efeitos do passado violento se prologam ao presente e podem ainda se estender ao futuro.

Essa perspectiva inscrita na tensão do passado que não passa atravessa de modo decisivo as duas obras literárias com as quais procuramos dialogar - K. Relato de uma busca, de Bernardo Kucinski que foi publicada em 2011 e A resistência de Julián Fuks, publicada em 2015 -, o que nos permite justificar a escolha efetuada. Os textos em questão constituem narrativas literárias recentes que têm se colocado a tarefa de testemunhar as feridas e os traumas no contexto das ditaduras da América Latina e que lutam, a seu modo, não apenas contra o apagamento de histórias violentas do passado, mas também como forma de reconstruir a própria vida dilacerada, ou seja, são capazes de conferir visibilidade às múltiplas configurações e experiências da violência individual e coletiva. 
Neste sentido, a operação heurística ocorre a partir das reflexões de Hans Ulrich Gumbrecht $^{25}$ que, a partir do contexto da Alemanha do pós-Segunda Guerra Mundial, procurou pensar o que significava "herdar um passado que não se quer, mas do qual não se consegue ficar excluído". Podemos lembrar aqui a metáfora do passageiro clandestino que o teórico nos apresenta:

\footnotetext{
Numa situação de latência, sempre há um passageiro clandestino, sentimos que existe alguma coisa (ou alguém) que não conseguimos agarrar ou tocar [...]. É impossível dizermos com precisão de onde nos vem a certeza dessa presença, tampouco sabemos afirmar exatamente onde está agora aquilo que é latente [...]. E, porque não conhecemos a identidade do objeto ou da pessoa latente, nada nos garante que reconheceríamos essa entidade se alguma vez viesse a revelar-se diante de nós [...], aquilo que está latente sofre transformações durante o tempo em que permanece oculto. Um passageiro clandestino envelhece, por exemplo. ${ }^{26}$
}

Gumbrecht aponta para a dimensão de uma presença inquietante que pode produzir efeitos, ao mesmo tempo que escapa à possibilidade de ser plenamente identificada e apreendida. O teórico chama a atenção, sobretudo, para a impossibilidade de encontrar uma relação equilibrada e segura com o vivido. A "atmosfera de latência" ou Stimmung de latência diz respeito àquilo que pode tornar o passado uma "coisa presente - imediata e intuitivamente presente" ${ }^{27}$. Essa sensibilidade sinaliza para inquietações profundas que podem nos afetar de modo corpóreo, na medida em que desperta sentimentos de desconforto que dificilmente podem ser apreendidos de maneira precisa e integral. $\mathrm{O}$ passado que persiste e sobrevive no presente nunca é o mesmo. Assim como o passageiro clandestino que envelhece, o que resta atualiza-se no presente.

Como processo além do campo hermenêutico, ler um texto com a atenção voltada ao Stimmung significa que estaremos em abertura para outra dimensão textual que, mais que conferir sentidos e significações às coisas, pode provocar experiências e percepções capazes de envolver nossos corpos enquanto realidade física, suscitando "sensações interiores sem que questões de representação estejam necessariamente envolvidas", ${ }^{28}$

Vladimir Safatle e Edson Teles ${ }^{29}$ apontam que nosso recente passado violento é como espectro que assombra e ameaça o presente e que se manifesta nos traços de uma cultura política autoritária, nas múltiplas estratégias de esquecimento e denegação, nos elogios inacreditáveis à ditadura e nos usos insustentáveis do passado. O que se vê é a herança que nos resta de passados autoritários, violentos e inconclusos, como se algo "desse passado e de como se tornou parte do nosso presente nunca terá sossego". ${ }^{30}$ É justamente esse 
desassossego, esse desajuste temporal que aproximam as narrativas de Bernardo Kucinski e Julián Fuks, textos que desestabilizam as fronteiras entre os gêneros e trazem importantes reflexões sobre o passado violento, este que não conseguimos deixar para trás.

\section{As escritas da violência, "os ditos do sofrimento"}

O passado que não passa surge na narrativa de Júlian Fuks, em particular, na inquietante indagação: "Pode um exílio ser herdado?". 31 A escrita, que é também uma busca identitária, incita a procura pelo passado assinalado pelas incertezas, descontinuidades e dimensões da memória e do trauma. A Resistência (2015), obra que recebeu o Prêmio Jabuti na categoria Ficção do Ano em 2016, desafia as fronteiras entre os gêneros apresentando-se como escrita híbrida.

Nas complexas relações entre passado e presente, o livro nos apresenta os conflitos familiares do escritor, a resistência dos seus pais à ditadura na Argentina, seus "deslocamentos incessantes", as "moradas provisórias", a adoção do irmão ainda na Argentina, a complexidade que ela representa levando em consideração a resistência do irmão ao convívio familiar, a fuga dos pais perseguidos pela ditadura argentina em 1976 e a vinda para o Brasil, à época também marcado por perseguições, tortura e desaparecimentos.

$\mathrm{Na}$ ambivalência da escrita, os percursos da memória fragmentada, afetiva e lacunar mobilizam histórias pessoais que se somam às questões experimentadas também na esfera social, na tensão e incapacidade de encontrar uma relação estável com o passado: "Seríamos nós, os pequenos, tão expatriados quanto nossos pais? Devíamos nos considerar argentinos privados do nosso país, da nossa pátria? Estará também a perseguição política submetida às normas da hereditariedade?".32

O escritor e crítico literário - doutor em Teoria Literária pela Universidade de São Paulo - nasceu no Brasil em 1981 e não sofreu diretamente os traumas da tortura e da perseguição política das ditaduras, mas se apresenta como herdeiro do exílio ${ }^{33}$ a que seus pais foram submetidos, o que denomina "ato imposto pela força". A narrativa vem atravessada pela angústia do não pertencimento, numa relação ambivalente que deseja recobrar o que ele considera que lhe foi, "indiretamente, talvez, roubado"34: 
lugar algum, nada reparará o que vivi, pois não parece haver nada a ser reparado em mim. ${ }^{35}$

Julián Fuks ${ }^{36}$ busca não apenas transformar a matéria autobiográfica em matéria literária, mas avança sobre outras direções, afinal "o narrar testemunha, o narrar disserta, o narrar critica, o narrar opina”. A escrita que, inicialmente, tinha a intenção de abordar, a pedido do irmão, a adoção e as dificuldades das relações familiares, sonda os vestígios do passado que habitam sua existência e as histórias da família. Parte do passado que o aflige vem das histórias não vividas, histórias ouvidas, recordações precárias desencadeadas por objetos, fotografias e imagens "esmaecidas" que denunciam a própria fragilidade na busca pela compreensão do vivido: "vidas complexas que se entrelaçam e se permeiam com um passado coletivo, com a marcha de uma época, com as tortuosas fissuras de um tempo". ${ }^{37}$

Em capítulos curtos de estrutura fragmentada, a narrativa rememora as fraturas do vivido que não pode ser restituído por inteiro. Ao evocar os sofrimentos dos pais e as violências perpetradas pela ditadura argentina, experimentando pela escrita, uma revisão dos sentidos do passado individual, familiar e coletivo, o que se percebe é o caráter intangível do que se foi. Assim, a escrita surge como uma das formas plurais para este enfrentamento.

Como afirma Fuks, o livro é duplo em cada linha. Nele, as tragédias pessoais e coletivas se entrelaçam e somos afetados pelas "cicatrizes" do vivido, o déficit da linguagem, as lembranças vagas, os interditos, as inquietações, as interrogações sem respostas, o "luto discreto" que a mãe vivenciava, as "mortes incompletas", sem corpos, os "lutos obstruídos", as "histórias não contadas", "os pensamentos insondáveis", os "silêncios pouco memoráveis", a "atrocidade de um regime que mata também a morte dos assassinados", o peso do exílio e a "culpa própria dos que se salvaram". ${ }^{38} \mathrm{O}$ passado persiste e adentra o presente em enunciados que testemunham a própria incapacidade de testemunhar. Certo de que as palavras deformam, a resistência, de que nos fala o título, se constrói com o que resta:

Quase tudo o que me dizem, retiram; quase tudo o que quero lhes dizer se prende à garganta e me desalenta. ${ }^{39}$

Isto não é uma história. Isto é história. Isto é história e, no entanto, quase tudo o que tenho ao meu dispor é a memória, noções fugazes de dias tão remotos, impressões anteriores à consciência e à linguagem, resquícios indigentes[...]: sei bem que nenhum livro jamais poderá contemplar ser humano nenhum, jamais constituirá em papel e tinta sua existência feita de sangue e de carne. ${ }^{40}$

Mas há pesares que não sucumbem a argumentos, há dores que não se enxergam. Há histórias que não se inventam [...], histórias que recusam a proximidade com a leveza [...]. Há casos que não habitam a superfície da memória e que, no entanto, 
não se deixam esquecer, não se deixam recalcar [...]. Às vezes, no espaço de uma dor cabe apenas o silêncio. Não um silêncio feito da ausência das palavras: um silêncio que é a própria ausência. ${ }^{41}$

$\mathrm{O}$ que pode ser apreendido é que o passado que se quer acessar não se prende. $\mathrm{O}$ passado é também ficção na medida em que, como nos diz Jacques Rancière, ${ }^{42}$ "o real precisa ser ficcionado para ser pensado". A partir das condições de sensibilidade do passado, Julián Fuks contribui para a compreensão do enredamento das relações entre presente e passado e nas suas formulações parece ensejar uma ficção que não seja vista como oposta à verdade, mas que se volta para mostrar a sua própria complexidade. ${ }^{43}$

Podemos perceber situação correlata em K. Relato de uma busca (2011), de Bernardo Kucinski. A abertura do texto ocorre a partir de epígrafe bastante significativa: "Caro leitor: tudo neste livro é invenção, mas quase tudo aconteceu". ${ }^{44}$ A narrativas de Kucinski, assim como A resistência (2015), desestabilizam e embaralharam os campos, operando formas plurais em territórios partilhados.

Em sua obra, o jornalista Bernardo Kucinski rememora o desaparecimento da irmã Ana Rosa Kucinski, professora universitária e militante da Ação Libertadora Nacional (ALN). Ana Rosa foi presa pelos agentes do Estado, juntamente com o marido Wilson Silva, em 22 de abril de 1974 e nunca mais foram vistos. O desaparecimento obscuro se arrasta ainda nos dias de hoje, apesar das investigações da Comissão Nacional da Verdade (2012-2014). ${ }^{45} \mathrm{O}$ livro que traz a procura insistente do pai, K., pela filha A., desaparecida na ditadura, inaugura os escritos literários do então jornalista que trabalhou em jornais alternativos no período ditatorial, entre eles o Opinião e o Movimento. Kucinski é ainda autor de vários livros sobre jornalismo e política, como Jornalistas e Revolucionários: nos tempos da imprensa alternativa (1991).

Logo nas páginas iniciais, o leitor se depara com a força das palavras que insistem em contar vidas que se foram:

De tempos em tempos, o correio entrega no meu antigo endereço uma carta de banco a ela destinada [...]. Sempre me emociono à vista de seu nome no envelope. E me pergunto: como é possível enviar reiteradamente cartas a quem inexiste há mais de três décadas? [...]

É como se as cartas tivessem a intenção oculta de impedir que sua memória na nossa memória descanse; como se além de nos haverem negado a terapia do luto, pela supressão do seu corpo morto, o carteiro fosse um Dybbuk, sua alma em desassossego, a nos apontar culpas e omissões. Como se além da morte desnecessária quisessem estragar a vida necessária, esta que não cessa e que nos demandam nossos filhos e netos.

[...] Sei que as cartas à destinatária ausente continuarão a chegar. O carteiro nunca saberá que a destinatária não existe; que foi sequestrada, torturada e 
assassinada pela ditadura militar [...]. O nome no envelope selado e carimbado, como a atestar a autenticidade, será o registro tipográfico não de um lapso ou falha do computador, e sim um mal de Alzheimer nacional. Sim, a permanência do seu nome do rol dos vivos será, paradoxalmente, produtor do esquecimento coletivo do rol dos mortos. ${ }^{46}$

Em capítulos aparentemente autônomos, marcados pela descontinuidade, encontramos várias vozes narrativas: carcereiros, torturadores, professores da USP, entre outros. O pai "tateia como um cego o labirinto inesperado da desaparição" numa procura desesperada para obter informações sobre a filha, momentos que envolvem situações de mentiras, tentativas de extorsões e a conivência da Universidade de São Paulo com os órgãos da repressão. Diversos sentimentos podem ser vislumbrados como a percepção do medo das pessoas em ouvir a própria história do desaparecimento da filha: "Falavam aos sussurros, sem completar as frases, como se cada palavra escondesse mil outras de sentidos proibidos". ${ }^{47}$ A família já atormentada pelo trauma do genocídio judeu na Segunda Guerra Mundial (o pai K. é um judeu polonês que veio para o Brasil fugindo do regime nazista) viveria os dilemas da violência da ditadura e a impossibilidade de elaboração da perda.

A narrativa confronta o passado e traz o luto impossível, um luto sem corpo. Escancara as dificuldades para encontrar pistas do que aconteceu e evoca os múltiplos mecanismos e estratégias adotadas pelo Estado brasileiro para a culpabilização não somente das vítimas, mas também das famílias. ${ }^{48}$

Porque é óbvio que o esclarecimento dos sequestros e execuções, de como e quando se deu cada crime, acabaria com a maior parte daquelas áreas sombrias que fazem crer que, se tivéssemos agido diferentemente do que agimos, a tragédia teria sido abortada.

Por isso, também as indenizações às famílias dos desaparecidos - embora mesquinhas - foram outorgadas rapidamente, sem que eles tivessem que demandar, na verdade antecipando-se a uma demanda para enterrar logo cada caso. Enterrar os casos sem enterrar os mortos, sem abrir espaço para uma investigação. Manobra sutil que tenta fazer de cada família cúmplice involuntária de uma determinada forma de lidar com a história. ${ }^{49}$

Nas disputas pelo vivido, a narrativa testemunha, a um só tempo, a ausência do corpo e a presença do passado e luta, a seu modo, para "derrubar o muro de silêncio em torno do sumidouro de pessoas". Espécie de "muralha impenetrável" que, quarenta anos depois estaria ainda de pé, intocada, como nos conta uma voz narrativa do futuro: "Essas perguntas ficarão para sempre sem respostas. Nem se saberá com precisão, mesmo décadas depois, como foram sequestrados e mortos". 50 
Conforme Ettore Finazzi Agrò, ${ }^{51}$ a tarefa que parte da literatura brasileira mais recente atribuiu a si mesma tem sido a vontade de testemunhar, através da escrita, as feridas e as marcas que a ditadura militar nos deixou. Neste sentido, Kucinski evoca "as exigências impossíveis de verdade", tendo em vista a violência da repressão do Estado brasileiro e seus métodos de destruição e aniquilamento do corpo e da verdade. Diz muito das fraturas que o sofrimento provoca e que constitui a "falência de toda busca por uma verdade apagada e impossível de ser recuperada - como, aliás, o corpo e a voz (ou o grito) das vítimas". ${ }^{52}$ Ditos do sofrimento, morte como "sentimento do arrancamento" que, para Arlette Farge, ${ }^{53}$ tem implicações sociais e políticas que pertencem plenamente à história e, neste caso, o testemunho é a busca de um alívio que nunca se completa.

Questões que nos lembram que a violência da ditadura, longe de desaparecer, resultou disseminada na sociedade, em especial, quando se considera a cultura da impunidade e os legados políticos e sociais desse período que insistem em permanecer, pois conservam as práticas violentas e, ao mesmo tempo, articulam formas de ressignificar o passado e transformar a memória do que passou. ${ }^{54}$

De acordo com Mariana Scaramucci, ${ }^{55}$ Bernardo Kucinski realiza a tarefa testemunhal que a personagem K. não conseguiu completar. A obra opera a tentativa de restituição da impossibilidade de dar ao luto a sua materialidade física. O texto literário desafia a impossibilidade de recuperar de forma integral o corpo e a memória e apresenta-se, de maneira parcial e incompleta, a fixação do luto no espaço do texto. Conforme mencionou Beatriz Sarlo, ${ }^{56}$ os textos literários existem e são "obstáculos levantados contra o convite ao esquecimento, contra sua possibilidade ou imposição; teimam em opor-se à hipocrisia de uma reconciliação amnésica que pretende calar o que, de qualquer modo, já se sabe”. Na narrativa de perguntas sem repostas, restam as "áreas sombrias" que, para Kucinski, trazem a insegurança do passado e sua insistência:

Também os sobreviventes daqui estão sempre a vasculhar o passado em busca daquele momento em que poderiam ter evitado a tragédia e por algum motivo falharam [...]. O "totalitarismo institucional" exige que a culpa, alimentada pela dúvida e opacidade dos segredos, e reforçada pelo recebimento das indenizações, permaneça dentro de cada sobrevivente como drama pessoal e familiar, e não como a tragédia coletiva que foi e continua sendo, meio século depois. ${ }^{57}$

Os sobreviventes carregam consigo a culpa, quando ela deveria ser enfrentada como um trauma coletivo. Como tragédias individuais e coletivas, as duas obras podem ser vistas 
como reação ao silenciamento na cena pública dos horrores praticados e que trazem a possibilidade, mesmo que precariamente, de contribuir para a constituição de uma cultura da memória. O testemunho é parte de uma complexa política de memória ${ }^{58}$ e estabelece importante zelo ético e político, o que significa também a luta contra o esquecimento e a denegação.

Arlette Farge nos lembra que a dor significa e a maneira como a sociedade a capta ou a recusa é extremamente importante. ${ }^{59}$ A história também é feita da opacidade, do que mal se vê, mas que nem por isso deixa de atestar sua presença. Neste sentido, o que a história e seu ensino podem fazer com o encontro de palavras que exprimem a dor e o sofrimento? Como ler escritas que envolvem conformações sociais violentas? Muitas vezes nos voltamos para os fatos e os acontecimentos, mas o sofrimento e suas implicações psíquicas e sociais tendem a ficar de fora do relato histórico.

Do encontro/confronto entre passado e presente, na fragilidade de suas fronteiras, os não ditos da história, os "inomináveis" e os "invisíveis" solapam a linguagem; em algumas circunstâncias só o excesso de palavras tomadas às atribuições da literatura poderiam permitir, na concepção de Jacques Rancière, ${ }^{60}$ uma possível aproximação da escrita da história à complexidade da vida social, pela dificuldade e/ou impossibilidade de se apreender integralmente qualquer experiência humana, em especial, as que envolvem a dor e o sofrimento. Na produção literária, tão tangível como o suporte físico, as ideias, as imagens e os enunciados modificam maneiras de ver, sentir e dizer, plasmando, histórica e esteticamente, um repertório de posturas que podem atuar no estabelecimento de orientações éticas individuais e coletivas, numa relação entre estética e ética.

Neste sentido, enfatizamos a importância do estudo de temas sensíveis. E a literatura, deste modo, pode contribuir de maneira significativa para "despertar um posicionamento ético e político, de indignação frente à injustiça e à violação dos direitos humanos mais fundamentais". ${ }^{61}$ Mover a aula de história para o campo da ética significa impactar, provocar sensações, acometer a dimensão afetiva dos sujeitos e criar experiências de vida, pois a aprendizagem significativa implica também uma transformação subjetiva, uma transformação de si. Afinal, a história, como produtora de subjetividades, constitui saberes e práticas que se coadunam às questões éticas e políticas. 


\section{Conclusão}

Do discurso literário temos mais que representação do passado, pois é ação que instaura uma intervenção política. ${ }^{62}$ Da multiplicidade que se oferece, destacamos o valor da literatura no sentido de lançar luz sobre episódios violentos e de difícil acolhimento na esfera do pensamento, na medida em que pode participar da construção do pensamento plural e de um repertório mais humano e ético, em especial quando se trata da sociedade brasileira recorrentemente marcada pela violência e pela negação dos rastros dessa mesma violência. ${ }^{63}$

Contar história(s) é também uma forma de acolher e de ativar a circulação de (in)visibilidades. Como nos lembra Julián Fuks:64 "A literatura se faz nessa busca. [...] uma dívida com o passado que a literatura não vai saldar", mas que pode encontrar palavras e isso “já é transformar”. Os textos de Bernardo Kucinski e Julián Fuks participam de maneira expressiva do campo das reflexões sobre a memória, as políticas de memória e as relações entre história e ficção.

Assim como a literatura pode reforçar o enfrentamento da violência, a didática da história, na medida em que parte de uma perspectiva ampla que procura pensar não somente o ensino e a aprendizagem, mas também os usos públicos e políticos que se faz do passado, pode impulsionar o pensamento histórico como vinculado ao horizonte de tempo que lhe é coetâneo e que constitui sentido para a vida humana. Desta forma, ao compreender o passado, podemos reconstruir uma história "para o presente".

Conforme aprendemos com Arlette Farge, ${ }^{65}$ interrogar o passado é também manifestar “o desejo de uma história inervada pelo tempo". Há lugares para a história que permitem confrontar passado e presente indagando de outros modos os deslocamentos, as descontinuidades e as fissuras, buscando entrelaçar "o que desaparece com o que aparece". Lugares para a história que reverberam na atualidade e levam em conta, nos traços do passado/presente, os "modos singulares de existir ou de ser e estar no mundo".

Mais que ferramentas de conhecimento, a didática da história e a literatura estão emaranhadas ao político, ao sensível e ao estético. Trata-se de múltiplos saberes e tramas que, no interior de conformações sociais violentas, constituem espaços de resistências e (re)existências que podem mobilizar novas racionalidades para pensar o outro. Deste modo, podem ainda traduzir a elaboração de processos sociais individuais e coletivos que estabelecem vínculos entre o vivido e o presente, certos de que "não há outra história além daquela que fala por nós". 66 
Importante destacar que o texto literário não é entendido somente na condição de fonte de pesquisa, mas objeto de reflexão. Na textura da escrita e do vivido, a partir de uma proposta que não pretende separar história e literatura, procuramos articular passado e presente, refletindo sobre experiências traumáticas de sofrimento e violência - as de ontem e as de hoje - e que, visibilizadas pela literatura e pela história, reforçam a necessidade de uma política de memória literária e do ensino de história como lugares de resistência no importante desafio de educar para a defesa da vida e dos direitos humanos.

\section{Notas}

1 WANDERLEY, Sonia. Didática da História Escolar: Um debate sobre o caráter público da história ensinada. In: ALMEIDA, Juniele Rabêlo; MENESES, Sônia (org.). História Pública em debate: Patrimônio, educação e mediações do passado. São Paulo: Letra e Voz, 2018, p.98.

${ }^{2}$ PROST, Antoine. [1996] Doze lições sobre a história. Trad. Guilherme João de Freitas Teixeira. $2^{\mathrm{a}}$ ed. Belo Horizonte: Autêntica Editora, 2012, p. 13.

${ }^{3}$ PENNA, Fernando de Araújo; FERREIRA, Rodrigo de Almeida. O trabalho intelectual do professor de história e a construção democrática: Práticas de História Pública frente à Base Nacional Comum Curricular e ao Escola sem Partido. In: ALMEIDA, Juniele Rabêlo; MENESES, Sônia (org.). História Pública em debate: Patrimônio, educação e mediações do passado. São Paulo: Letra e Voz, 2018, p. 109.

${ }^{4}$ MENESES, Sonia. Bolsanarismo: um problema "de verdade" para a história. In: KLEN, Bruna; PEREIRA, Mateus; ARAÚJO, Valdei (org.) Do fake ao fato: des(atualizando) Bolsonaro. Vitória: Milfontes, 2020. E-book.

${ }^{5}$ RÜSEN, Jörn. Didática da história: passado, presente e perspectivas a partir do caso alemão. In: SCHMIDT, Maria Auxiliadora; BARCA, Isabel; MARTINS, Estevão de Resende (org.). Jörn Rüsen e o ensino de história. Curitiba: Ed. UFPR, 2010. p.23-40.

${ }^{6}$ SADDI, Rafael. Didática da história na Alemanha e no Brasil: considerações sobre o ambiente de surgimento da Neu Geschichtsdidaktik na Alemanha e os desafios da nova Didática da História no Brasil. OPSIS, 14(2), 2014, p. 140-141.

${ }^{7}$ CERRI, Luis Fernando. Os Conceitos de consciência histórica e os desafios da didática da história. Revista de História Regional, v. 6, n. 2, p. 93-112, 2001, p. 110.

${ }^{8}$ RÜSEN, Jörn. Razão histórica: teoria da história: os fundamentos da ciência histórica. Tradução de Estevão de Rezende Martins. Brasília: Editora da UnB, 2001, p. 57.

${ }^{9}$ CERRI, Luis Fernando. Os Conceitos de consciência histórica e os desafios da didática da história. Revista de História Regional, v. 6, n. 2, p. 93-112, 2001, p. 120.

${ }^{10}$ VIEIRA, Vera Lúcia Silva; NUNES, Radamés Vieira. O mal de Alzheimer nacional: algumas reflexões sobre os usos políticos do passado e o ensino de história. Revista Caminhos da História. v.23, n.2 jul./dez.2018). p.2948.

${ }^{11}$ NAPOLITANO, Marcos. Negacionismo e revisionismo histórico no século XXI. In: PINSKY, Jaime; PINSKY, Carla Bassanezi; FICO, Carlos et al. (org.). Novos combates pela história: desafios, ensino. São Paulo: Contexto, 2021, p.85-111.

12 BENJAMIN, Walter. Sobre o conceito de história. In: $O$ anjo da história: Walter Benjamin. Trad. João Barrento. Belo Horizonte: Autêntica. 2012. p. 11.

${ }^{13}$ SELIGMANN-SILVA, Márcio. Imagens precárias: inscrições tênues de violência ditatorial no Brasil. In. Estudos de literatura brasileira contemporânea, n. 43, p. 13-34, jan./jun. 2014, p. 30.

${ }^{14}$ MENESES, Sonia. Bolsonarismo: um problema "de verdade" para a história. In: KLEN, Bruna; PEREIRA, Mateus; ARAÚJO, Valdei (org.) Do fake ao fato: des(atualizando) Bolsonaro. Vitória: Milfontes, 2020. E-book (não paginado).

${ }^{15}$ SELIGMANN-SILVA, Márcio. Imagens precárias: inscrições tênues de violência ditatorial no Brasil. In. Estudos de literatura brasileira contemporânea, n. 43, p. 13-34, jan./jun. 2014. 
${ }^{16}$ PEREIRA, Mateus Henrique de Faria. Nova direita? Guerras de memória em tempos de Comissão da Verdade (2012-2014). In: Varia História, Belo Horizonte, vol. 31, n. 57, p. 863-902, set/dez 2015. Disponível em: http://www.scielo.br/scielo.php?script=sci_arttext\&pid=S0104-87752015000300863. Acesso em: 08/abr./2016.

${ }^{17}$ BAUER, Carolina Silveira. Como será o passado? História, Historiadores e a Comissão Nacional da Verdade. 1ed. Jundiaí, SP: Paco, 2017.

${ }^{18}$ GUIMARÃES, Manoel Luiz Salgado. Prefácio. In: ALBUQUERQUE JUNIOR, Durval Muniz. História: A arte de inventar o passado. Ensaios de teoria da história. Bauru, SP: Edusc, 2007, p. 17.

${ }^{19}$ GINZBURG, Jaime. A violência constitutiva e a política do esquecimento. In: GINZBURG, Jaime. Crítica em Tempos de Violência. São Paulo: Edusp, 2012, p.220.

${ }^{20}$ CEZAR, Temístocles. Tempo presente e usos do passado. In: VARELLA, Flávia Florentino et al. (org.) Tempo presente \& usos do passado. Rio de Janeiro: Editora FGV, 2012. E-book (não paginado).

${ }^{21}$ GINZBURG, Jaime. Literatura Brasileira após Auschwitz. In: GINZBURG, Jaime. Crítica em Tempos de Violência. São Paulo: Edusp, 2012, p.207-215.

${ }^{22}$ GINZBURG, Jaime. A violência constitutiva e a política do esquecimento. In: GINZBURG, Jaime. Crítica em Tempos de Violência. São Paulo: Edusp, 2012, p.220.

${ }^{23}$ GAGNEBIN, Jeanne Marie. O que significa elaborar o passado. In: GAGNEBIN, Jeanne Marie. Lembrar escrever esquecer. São Paulo: Editora 34, 2006. p. 97-105.

${ }^{24}$ SEFFNER, Fernando; PEREIRA, Nilton Mullet Pereira. Ensino de história: passados vivos e educação em questões sensíveis. Revista História Hoje, v. 7, nº13, p.14-33. 2018, p.17. Disponível em: https://rhhj.anpuh.org/RHHJ/article/view/427/275. Acesso em: 07 fev. 2019.

${ }^{25}$ GUMBRECHT, Hans Ulrich. Depois de 1945: latência como origem do presente. Trad. Ana Isabel Soares. 1ed. São Paulo: Editora Unesp, 2014, p. 344.

${ }^{26}$ GUMBRECHT, Hans Ulrich. Depois de 1945: latência como origem do presente. Trad. Ana Isabel Soares. 1ed. São Paulo: Editora Unesp, 2014, p. 40.

${ }^{27}$ GUMBRECHT, Hans Ulrich. Depois de 1945: latência como origem do presente. Trad. Ana Isabel Soares. 1ed. São Paulo: Editora Unesp, 2014, p.42.

${ }^{28}$ GUMBRECHT, Hans Ulrich. Atmosfera, ambiência, Stimmung: Sobre um potencial oculto da literatura. Trad. Ana Isabel Soares. 1.ed. Rio de Janeiro: Contraponto: Editora PUC Rio, 2014, p.14.

${ }^{29}$ TELES, Edson; SAFATLE, Vladimir (Org.). O que resta da ditadura: a exceção brasileira. São Paulo: Boitempo, 2010, p.10.

${ }^{30}$ GUMBRECHT, Hans Ulrich. Depois de 1945: latência como origem do presente. Trad. Ana Isabel Soares. 1ed. São Paulo: Editora Unesp, 2014, p.50.

${ }^{31}$ FUKS, Julián. A resistência. São Paulo: Companhia das Letras, 2015, p. 19.

${ }^{32}$ FUKS, Julián. A resistência. São Paulo: Companhia das Letras, 2015, p. 15.

${ }^{33}$ FIGUEIREDO, Eurídice. A resistência, de Julián Fuks: uma narrativa de filiação. Estudos de Literatura Brasileira Contemporânea. Brasília, n.60, e6005, 2020.

${ }^{34}$ FUKS, Julián. A resistência. São Paulo: Companhia das Letras, 2015, p. 15.

${ }^{35}$ FUKS, Julián. A resistência. São Paulo: Companhia das Letras, 2015, p. 131.

${ }^{36}$ FUKS, Julián. A era da pós-ficção: notas sobre a insuficiência da fabulação no romance contemporâneo. In: DUNKER, Christian et al. Ética e pós-verdade. Porto Alegre: Dublinense, 2017, p. 70.

${ }^{37}$ FUKS, Julián. A resistência. São Paulo: Companhia das Letras, 2015, p. 35.

${ }^{38}$ FUKS, Julián. A resistência. São Paulo: Companhia das Letras, 2015, p. 78-88.

${ }^{39}$ FUKS, Julián. A resistência. São Paulo: Companhia das Letras, 2015, p. 40.

${ }^{40}$ FUKS, Julián. A resistência. São Paulo: Companhia das Letras, 2015, p. 23.

${ }^{41}$ FUKS, Julián. A resistência. São Paulo: Companhia das Letras, 2015, p. 75

${ }^{42}$ RANCIÈRE, Jacques. A partilha do sensível: Estética e política. Trad. Mônica Costa Netto. São Paulo: Editora 34, 2005. p.58.

${ }^{43}$ FUKS, Julián. A era da pós-ficção: notas sobre a insuficiência da fabulação no romance contemporâneo. In: DUNKER, Christian et al. Ética e pós-verdade. Porto Alegre: Dublinense, 2017, p. 67-85.

${ }^{44}$ KUCINSKI, Bernardo. K. Relato de uma busca. São Paulo: Companhia das Letras, 2016, p.11.

${ }^{45}$ Sobre Ana Rosa Kucinski, Cf. http://comissaodaverdade.al.sp.gov.br/mortos-desaparecidos/ana-rosa-kucinskisilva.

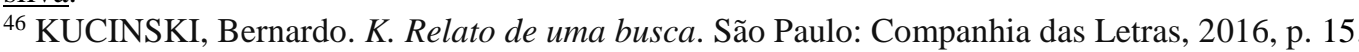

${ }^{47}$ KUCINSKI, Bernardo. K. Relato de uma busca. São Paulo: Companhia das Letras, 2016, p.19.

48 Cf. TELES, Janaína de Almeida. Os trabalhos da memória: os testemunhos dos familiares de mortos e desaparecidos políticos no Brasil. In: SELIGMANN-Silva, Márcio; GINZBURG, Jaime; HARDMAN, Francisco Foot (org.) Escritas da violência: representações da violência na história e na cultura contemporâneas da América Latina. Vol. II. Rio de Janeiro: 7Letras, 2012, p.109-118. 
${ }^{49}$ KUCINSKI, Bernardo. K. Relato de uma busca. São Paulo: Companhia das Letras, 2016, p. 156.

${ }^{50}$ KUCINSKI, Bernardo. K. Relato de uma busca. São Paulo: Companhia das Letras, 2016, p.42.

51 FINAZZI-AGRÒ, Ettore. O corpo expropriado: Bernardo Kucinski - Diário de uma perda. Estudos de Literatura Brasileira Contemporânea, (60), e6001, Brasília, 2020.

52 FINAZZI-AGRÒ, Ettore. O corpo expropriado: Bernardo Kucinski - Diário de uma perda. Estudos de Literatura Brasileira Contemporânea, (60), e6001, Brasília, 2020. p. 03.

${ }^{53}$ FARGE, Arlette. Lugares para a história. Trad. Fernando Scheibe. 1 ed. Belo Horizonte: Autêntica, p. 16.

54 TELES, Edson; SAFATLE, Vladimir (Org.). O que resta da ditadura: a exceção brasileira. São Paulo: Boitempo, 2010, p.10.

${ }^{55}$ SCARAMUCI, Mariana. Monumentos precários: luto (im)possível e lápides de papel em K.: relato de uma busca. Estudos de Literatura Brasileira Contemporânea, (60), e6001, Brasilia, 2020.

56 SARLO, Beatriz. Paisagens imaginárias: intelectuais, arte e meios de comunicação. Trad. Miriam Senra. São Paulo: Edusp, 2016, p.32.

${ }^{57}$ KUCINSKI, Bernardo. K. Relato de uma busca. São Paulo: Companhia das Letras, 2016, p. 156.

${ }^{58}$ SELIGMANN-SILVA, Márcio. Narrar o trauma: a questão dos testemunhos de catástrofes históricas. Revista Psicologia Clínica. Rio de Janeiro: vol. 20, n.1, 2008, p.65-82.

${ }^{59}$ FARGE, Arlette. Lugares para a história. Trad. Fernando Scheibe. 1 ed. Belo Horizonte: Autêntica, p. 19.

${ }^{60}$ RANCIÈRE, Jacques. [1994] Os nomes da história: ensaio de poética do saber. Trad. Mariana Echalar. São Paulo: Unesp, 2014.

${ }^{61}$ PEREIRA, Nilton Mullet. Ensino de História, dever de memória e os temas sensíveis. In: Anais do II Seminário de Educação, Conhecimento e Processos Educativos. Disponível em: http://periodicos.unesc.net/seminarioECPE/index. Acesso em: 07/dez./2018. p. 2.

${ }^{62}$ FARIA, Daniel. O mito modernista. Uberlândia: EDUFU, 2006.

${ }^{63}$ VIEIRA, Vera Lúcia Silva Vieira. Poéticas do tempo, da memória e da história: Escritas da cidade e seus personagens nos diálogos de Ignácio de Loyola Brandão. 270 f. Tese (Doutorado em História) - Faculdade de Ciências Humanas e Sociais, Universidade Estadual Paulista. Franca, 2017.

${ }^{64}$ FUKS, Julián apud DIAS, Felício Laurindo. A situação da narrativa contemporânea hoje. Entrevista com Julián Fuks. SOLETRAS - Revista do Programa de Pós-Graduação em Letras e Linguística. n. 36 (jul.- dez. 2018). p.273-285. p. 284.

${ }^{65}$ FARGE, Arlette. Lugares para a história. Trad. Fernando Scheibe. 1 ed. Belo Horizonte: Autêntica, 2015 , p. 19-23.

${ }^{66}$ CLAVERO, Bartholomé apud FARGE, Arlette. Lugares para a história. Trad. Fernando Scheibe. 1 ed. Belo Horizonte: Autêntica, 2015. p.129.

\section{Referências}

BAUER, Carolina Silveira. Como será o passado? História, Historiadores e a Comissão Nacional da Verdade. 1ed. Jundiaí, SP: Paco, 2017.

BENJAMIN, Walter. Sobre o conceito de história. In: $O$ anjo da história: Walter Benjamin. Trad. João Barrento. Belo Horizonte: Autêntica. 2012. p. 9-20.

CERRI, Luis Fernando. Os Conceitos de consciência histórica e os desafios da didática da história. Revista de História Regional, v. 6, n. 2, p. 93-112, 2001.

CEZAR, Temístocles. Tempo presente e usos do passado. In: VARELLA, Flávia Florentino et al. (org.) Tempo presente \& usos do passado. Rio de Janeiro: Editora FGV, 2012. E-book.

DIAS, Felício Laurindo. A situação da narrativa contemporânea hoje. Entrevista com Julián Fuks. SOLETRAS - Revista do Programa de Pós-Graduação em Letras e Linguística. n. 36 (jul.- dez. 2018). p.273-285. p. 284. Disponível em: https://www.e-publicacoes.uerj.br. Acesso em 26 set. 2019. 
FARGE, Arlette. Lugares para a história. Trad. Fernando Scheibe. 1 ed. Belo Horizonte: Autêntica, 2015.

FARIA, Daniel. O mito modernista. Uberlândia: EDUFU, 2006.

FIGUEIREDO, Eurídice. A resistência, de Julián Fuks: uma narrativa de filiação. Estudos de Literatura Brasileira Contemporânea. Brasília, n.60, e6005, 2020.

FINAZZI-AGRÒ, Ettore. O corpo expropriado: Bernardo Kucinski - Diário de uma perda. Estudos de Literatura Brasileira Contemporânea, (60), e6001, Brasília, 2020.

FUKS, Julián. A resistência. São Paulo: Companhia das Letras, 2015.

FUKS, Julián. A era da pós-ficção: notas sobre a insuficiência da fabulação no romance contemporâneo. In: DUNKER, Christian et al. Ética e pós-verdade. Porto Alegre: Dublinense, 2017, p. 67-85.

GAGNEBIN, Jeanne Marie. O que significa elaborar o passado. In: GAGNEBIN, Jeanne Marie. Lembrar escrever esquecer. São Paulo: Editora 34, 2006. p. 97-105.

GINZBURG, Jaime. Crítica em Tempos de Violência. São Paulo: Edusp, 2012.

GUIMARÃES, Manoel Luiz Salgado Prefácio. In: ALBUQUERQUE JUNIOR, Durval Muniz. História: A arte de inventar o passado. Ensaios de teoria da história. Bauru, SP: Edusc, 2007. p. 15-18.

GUMBRECHT, Hans Ulrich. Depois de 1945: latência como origem do presente. Trad. Ana Isabel Soares. 1ed. São Paulo: Editora Unesp, 2014.

GUMBRECHT, Hans Ulrich. Atmosfera, ambiência, Stimmung: Sobre um potencial oculto da literatura. Trad. Ana Isabel Soares. 1.ed. Rio de Janeiro: Contraponto: Editora PUC Rio, 2014.

KUCINSKI, Bernardo. K. Relato de uma busca. São Paulo: Companhia das Letras, 2016.

MENESES, Sonia. Bolsonarismo: um problema "de verdade" para a história. In: KLEN, Bruna; PEREIRA, Mateus; ARAÚJO, Valdei (org.) Do fake ao fato: des(atualizando) Bolsonaro. Vitória: Milfontes, 2020. E-book.

NAPOLITANO, Marcos. Negacionismo e revisionismo histórico no século XXI. In: PINSKY, Jaime; PINSKY, Carla Bassanezi; FICO, Carlos et al. (org.). Novos combates pela história: desafios, ensino. São Paulo: Contexto, 2021, p.85-111.

PENNA, Fernando de Araújo; FERREIRA, Rodrigo de Almeida. O trabalho intelectual do professor de história e a construção democrática: Práticas de História Pública frente à Base Nacional Comum Curricular e ao Escola sem Partido. In: ALMEIDA, Juniele Rabêlo; 
MENESES, Sônia (org.). História Pública em debate: Patrimônio, educação e mediações do passado. São Paulo: Letra e Voz, 2018. p. 109-127.

PEREIRA, Mateus Henrique de Faria. Nova direita? Guerras de memória em tempos de Comissão da Verdade (2012-2014). In: Varia História, Belo Horizonte, vol. 31, n. 57, p. 863902, set/dez 2015. Disponível em: http://www.scielo.br/scielo.php?script=sci_arttext\&pid=S0104-87752015000300863. Acesso em: 08/abr./2016.

PEREIRA, Nilton Mullet. Ensino de História, dever de memória e os temas sensíveis. In: Anais do II Seminário de Educação, Conhecimento e Processos Educativos. Disponível em: http://periodicos.unesc.net/seminarioECPE/index. Acesso em: 07/dez./2018.

PROST, Antoine. [1996] Doze lições sobre a história. Trad. Guilherme João de Freitas Teixeira. $2^{\mathrm{a}}$ ed. Belo Horizonte: Autêntica Editora, 2012.

RANCIÈRE, Jacques. A partilha do sensível: Estética e política. Trad. Mônica Costa Netto. São Paulo: Editora 34, 2005.

RANCIÈRE, Jacques. [1994] Os nomes da história: ensaio de poética do saber. Trad. Mariana Echalar. São Paulo: Unesp, 2014.

RÜSEN, Jörn. Didática da história: passado, presente e perspectivas a partir do caso alemão. In: SCHMIDT, Maria Auxiliadora; BARCA, Isabel; MARTINS, Estevão de Resende (org.). Jörn Rüsen e o ensino de história. Curitiba: Ed. UFPR, 2010. p. 23-40.

RÜSEN, Jörn. Razão histórica: teoria da história: os fundamentos da ciência histórica. Tradução de Estevão de Rezende Martins. Brasília: Editora da UnB, 2001.

SADDI, Rafael. Didática da história na Alemanha e no Brasil: considerações sobre o ambiente de surgimento da Neu Geschichtsdidaktik na Alemanha e os desafios da nova Didática da História no Brasil. OPSIS, 14(2), 2014, p. 133-147.

SARLO, Beatriz. Paisagens imaginárias: intelectuais, arte e meios de comunicação. Trad. Miriam Senra. São Paulo: Edusp, 2016.

SCARAMUCI, Mariana. Monumentos precários: luto (im)possível e lápides de papel em K.: relato de uma busca. Estudos de Literatura Brasileira Contemporânea, (60), e6001, Brasília, 2020.

SEFFNER, Fernando; PEREIRA, Nilton Mullet Pereira. Ensino de história: passados vivos e educação em questões sensíveis. Revista História Hoje, v. 7, n⿳133, p.14-33. 2018, p.17. Disponível em: https://rhhj.anpuh.org/RHHJ/article/view/427/275. Acesso em: 07 fev. 2019.

SELIGMANN-SILVA, Márcio. Narrar o trauma: a questão dos testemunhos de catástrofes históricas. Revista Psicologia Clínica. Rio de Janeiro: vol. 20, n.1, 2008, p.65-82. 
SELIGMANN-SILVA, Márcio. Imagens precárias: inscrições tênues de violência ditatorial no Brasil. In. Estudos de literatura brasileira contemporânea, n. 43, p. 13-34, jan./jun. 2014.

TELES, Edson; SAFATLE, Vladimir (Org.). O que resta da ditadura: a exceção brasileira. São Paulo: Boitempo, 2010.

TELES, Janaína de Almeida. Os trabalhos da memória: os testemunhos dos familiares de mortos e desaparecidos políticos no Brasil. In: SELIGMANN-Silva, Márcio; GINZBURG, Jaime; HARDMAN, Francisco Foot (org.) Escritas da violência: representações da violência na história e na cultura contemporâneas da América Latina. Vol. II. Rio de Janeiro: 7Letras, 2012, p.109-118.

VIEIRA, Vera Lúcia Silva Vieira. Poéticas do tempo, da memória e da história: Escritas da cidade e seus personagens nos diálogos de Ignácio de Loyola Brandão. 270 f. Tese (Doutorado em História) - Faculdade de Ciências Humanas e Sociais, Universidade Estadual Paulista. Franca, 2017.

VIEIRA, Vera Lúcia Silva; NUNES, Radamés Vieira. O mal de Alzheimer nacional: algumas reflexões sobre os usos políticos do passado e o ensino de história. Revista Caminhos da História. v.23, n.2 jul./dez.2018). p.29-48.

WANDERLEY, Sonia. Didática da História Escolar: Um debate sobre o caráter público da história ensinada. In: ALMEIDA, Juniele Rabêlo; MENESES, Sônia (org.). História Pública em debate: Patrimônio, educação e mediações do passado. São Paulo: Letra e Voz, 2018. p. 95-118. 